the chemistry of sphingolipids, effect of gibberellins on morphogenesis of Cucumis sativis and the properties of polyelectrolyte-salt solutions.

\section{Organizing Scientific Research in Poland}

The Review of the Polish Academy of Sciences for April-June 1962 contains an article by J. Malocki describing the purpose and objects of the long-term plan for the Development of Science in Poland, the way work on the plan is being organized, and the measures being taken to develop a supply of the necessary scientific personnel and to organize the scientific research involved. The plan envisages an increasing use of 'directed' research during the next twenty years, but although in this context the word 'directed' is used in much the sense in which 'applied' is used in Britain, it appears to imply a certain amount of direction at least to the extent of ensuring effective use of expensive equipment and the avoidance of duplication of effort, as is done by the grants from the Department of Scientific and Industrial Research. Particular attention is also given to the encouragement of interdisciplinary effort. It is proposed to rely on relatively small but highly specialized teams. The same issue also includes an article by W. Nowacki: "Links between Science and Life". This discusses the general principles of scientific policy and the contribution of the Polish Academy of Sciences in particular, including the organization of fundamental and applied research and the problem of encouraging the application of results.

\section{Gordon Dean Memorial Fellowship Fund for Nuclear Science}

A MEmoriat fellowship fund has been created to honour the late Gordon Dean, former chairman of the U.S. Atomic Energy Commission and co-foundor of the Nuclear Science and Engineering Corporation. Former President Harry S. Truman has been elected honorary chairman of the Gordon Dean Memorial Fund, which will grant scholarships and fellowships for study and research in nuclear science. Until his untimely death in 1958 in a plane crash, Mr. Dean served as chairman of the board at Nuclear Science and. Engineering, which he founded with Mr. Brightsen in 1954. At the time of his death, he was also sonior vice-president of General Dynamics Corporation and an adviser on atomic energy to the investment banking firm of Lehman Brothers. Further information can bo obtained from the Nuclear Science and Engineering Corporation, P.O. Box 10901, Pittsburgh 36, Pennsylvania.

\section{The Night Sky in October}

FuLL moon occurs on Oct. 13d. 12h. 33m. U.T. and new moon on Oct. $28 \mathrm{~d}$. $13 \mathrm{~h}$. $05 \mathrm{~m}$. The following conjunctions with the Moon take place: Oct. 2d. 09h., Venus $11^{\circ}$ S.; Oet. 8d. 11h., Saturn 0.9 $9^{\circ}$ S.; Oet. 10d. 11h., Jupitor $1^{\circ}$ N.; Oct. 2ld. 01h., Mars $1^{\circ} \mathrm{N}$. In addition to these conjunctions with the Moon, Mercury is in conjunction with Spica on Oct. $30 \mathrm{~d}$. $21 \mathrm{~h}$., Mercury being $4^{\circ} \mathrm{N}$. Mercury is a morning star, visible low in the south-east before sunrise, and may be favourably observed during tho later part of the month when it rises nearly two hours before tho Sun. Venus is too close to the Sun for easy observa. tion. Mars rises at $22 \mathrm{~h}$. $55 \mathrm{~m} ., 22 \mathrm{~h} .40 \mathrm{~m}$. and $22 \mathrm{~h}$. $25 \mathrm{~m}$. on Oct. 1,15 and 31 , respectively. It is at a distance of 129 million miles on Octobor 15, and its stellar magnitude is +0.9 . Jupiter sets at $2 \mathrm{~h}$. $50 \mathrm{~m}$., 1h. $50 \mathrm{~m}$. and $0 \mathrm{~h} .50 \mathrm{~m}$. at the beginning, middle and end of the month, respectively. It is in Aquarius, its stellar magnitude is $-2 \cdot 3$ and its distance from the Earth in the middle of the month is 396 million miles. Saturn is in Capricornus, setting at 0h. 00m., 23h. $05 \mathrm{~m}$. and $22 \mathrm{~h} .05 \mathrm{~m}$. on Oct. 1,15 and 31 , respectively. Its stellar magnitudo is +0.7 and its distance from the Earth on October 15 is 898 million miles. Occultations of stars brighter than magnitude 6 are as follows, observations being made at Greenwich: Oct. 9d. 18h. 09.4m., $\delta$ Cap. $(R)$; Oct. 14d. 22h. 12.5m., $\mu$ Cet. $(D)$; Oct. 14 d. 22 h. 53.6 m., $\mu$ Cet. $(R)$; Oct. 21 d. 00 h. $26 \cdot 6 \mathrm{~m}$., $\theta$ Cne. $(R) . D$ and $R$ refer to disappearance and reappearance, respectively. 'The Orionid meteors are active during October 15--25, but conditions for observation are unfavourable.

\section{Announcements}

OPEn Days will be held at the National Chemical Laboratory, Teddington, on September 26 and 27. Further information can be obtained from the Chief Press Officer, Department of Scientific and Industrial Research, State House, High Holborn, London, W.C.1.

Tre second annual meeting of the American Society for Cell Biology will be hold at the Jack Tar Hotel, San Francisco, during November 5-7. Further information can be obtained from Dr. M. Alfert. Department of Zoology, University of California. Borkeley 4, California.

A symposium on "Fungi and their Metabolites" is to be held under the auspices of the Plant Phenolics Group and the British Mycological Society in the School of Pharmacy, London, W.C.1, on October 1 and 2. Further information can be obtained from Dr. J. G. Manners, Department of Botany, The University, Southampton.

The third Rapkine Memorial Lecture of the Institute of Biology will be delivered by Prof. F. Morel, of the French Centre for Nuclear Studies, Saclay. on October 8, at the French Institute, Queensberry Place, London, S.W.7. Further information can be obtained from the General Secretary, Institute of Biology, 41 Queen's Gate, London, S.W.7.

THE twelfth Dalton Lecture of the Royal Institute of Chemistry will be delivered by Sir Lawrence Bragg on October 24 in the Town Hall, Manchester. The title of Sir Lawrence's lecture will be "Living Molecules". Furthor information can be obtained from Mr. H. H. Armstrong, Science Department, College for Further Education, Wellington Road South, Stockport.

DR. J. H. VAN DER WAALS, Koninklijke/Shell Laboratorium, Amstordam, will deliver the following Bourke Lectures of the Faraday Society: "Study of the Phosphorescent State of Organic Molecules by Electron Resonance" (University of Nottingham on October 23 and University of Sheffield on October 26); "Clathrates as Elementary Solutions" (University of Oxford on October 30). Further information can be obtained from the Faraday Society, 6 Gray's Inn Square, London, W.C.1.

Erratum. In the communication entitled "Sto. matal Sensitivity to Low-Intensity Illumination in Xanthium pennsylvanicum", by Dr. 'T. A. Mansfield. which appeared on p. 514 of the August 4 issue of Nature, the second sentence of the first paragraph should read, "The rhythm was shown ... 10 lux given. instead of darkness was sufficient to delay its progress". 